\title{
Electrochemical Polishing of Extruded and Laser Powder-Bed-Fused Inconel 718
}

\author{
Srishti Jain, James Hyder, Mike Corliss and Wayne Hung
}

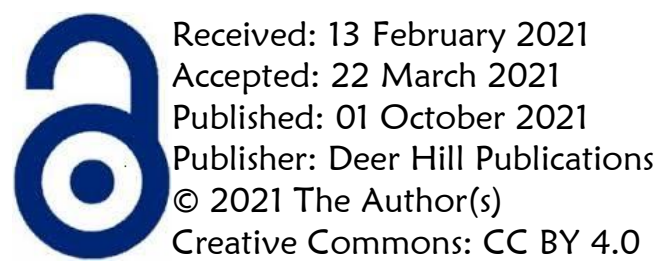

\begin{abstract}
Electro-chemical polishing (ECP) was utilized to produce sub-micron surface finish on Inconel 718 parts manufactured by Laser Powder-Bed-Fusion (L-PBF) and extrusion methods. The L-PBF parts had very rough surfaces due to semiwelded powder particles, surface defects, and difference layer steps that were generally not found on surfaces of extruded and machined components. This study compared the results of electro-polishing of these differently manufactured parts under the same conditions. Titanium electrode was used with an acid-based electrolyte to polish both the specimens at different combinations of pulsed current density, duty cycle, and polishing time. Digital 3D optical profiler was used to assess the surface finish, while optical and scanning electron microscopy was utilized to observe the microstructure of polished specimens. At optimal condition, the ECP successfully reduced the surface of L-PBF part from $17 \mu \mathrm{m}$ to $0.25 \mu \mathrm{m}$; further polishing did not improve the surface finish due to different removal rates of micro-leveled pores, cracks, nonconductive phases, and carbide particles in 3D-printed Inconel 718 . The microstructure of extruded materials was uniform and free of processing defects, therefore can be polished consistently to $0.20 \mu \mathrm{m}$. Over-polishing of extruded material could improve its surface finish, but not for the L-PBF material due to defects and the surrounding micro-strain.
\end{abstract}

Keywords: Laser Powder Bed Fusion, Selective Laser Melting, Electro-chemical polishing, Surface roughness, Extrusion, Inconel 718, Microstructure.

\section{INTRODUCTION}

Metal Additive Manufacturing (MAM) have become more popular in industry and academia since it can produce complex shaped metal components using one platform without having to integrate many different manufacturing techniques. The Inconel 718 (IN 718) superalloy possesses properties suitable for extreme environments in nuclear, chemical, oil/gas and aerospace applications. Owing to its superior properties such as corrosion and creep resistance at elevated temperatures, the IN 718 are highly demanded material for complex engineering profiles, robust and with high dimensional precision [1]. Consolidation of Inconel powder by AM techniques has helped in producing IN 718 parts while preserving material properties and allowing more design freedom. A variety of powder-bed AM methods such as electron beam melting, direct energy depositing, selective laser sintering, binder jetting, and selective laser melting (SLM) -or laser powder bed fusion (L-PBF) -- are suitable for this purpose. However, parts produced through these methods are far from finished products due to their rough surfaces and dimensional inaccuracy. The rough surface is a result of shrinkage, layer wise building sequence or "staircase effect," partially welded powder particles, cracks and slags.

Optimizing the AM parameters and scanning strategies can only improve the surface finish to some extent $[2,3]$, but to achieve the required level of submicron surface finish would necessitate the need of post processing of MAM parts. For examples, dimensioning accuracy and good surface finish are required for applications such as aircraft engines, high-pressure turbines, or medical implants. These post processing operations could include machining, buffing, grinding, lapping, chemical mechanical planarizing (CMP), magnetic particle polishing and electrochemical polishing (ECP). Finish machining of IN 718 can reduce the as-printed surface finish from 17-20 $\mu \mathrm{m}$ to about $1.5 \mu \mathrm{m}$

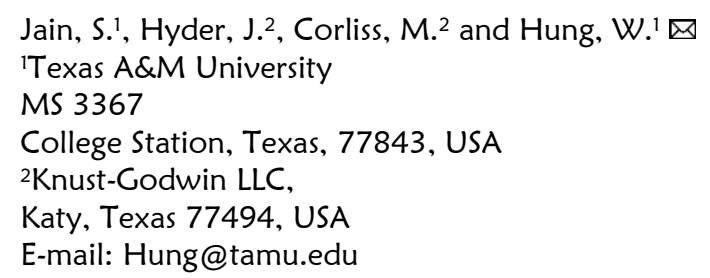


Sa but at the expense of tool wear [4]. Another preliminary study showed that buffing can produce a submicron surface finish but corners and specimen details could be indiscriminately polished. Similar issues are expected for the abrasive flow polishing. Although grinding, lapping, CMP, or magnetic particle polishing can be applied to polish additively printed specimens, these processes are more suitable to large components with restricted or very specific and simple geometries. The ECP process is a promising technique due to its non-contact nature, non-consumable electrode, independence of workpiece strength and hardness, no surface damage, and no process-induced residual stress. This process can be applied locally to polish only a critical surface, or to improve the larger surface of an engineering component with customized electrodes. The ECP also eliminates additional deburring process compared to using a contact-method for surface enhancement.

Post processing techniques including ECP have been applied to Inconel alloys that were fabricated by either extruding, rolling, forging, or casting but very limited published data were found for polishing of 3D-printed IN 718. This research aims to:
i. Achieve submicron surface finish of IN 718 by ECP.
ii. Compare the polishing results on IN 718 samples fabricated by L-PBF or extrusion, and
iii. Correlate polishing results with the microstructural study on ECP specimens.

\section{LITERATURE REVIEW}

Inconel comes from a family of austenitic-nickel-chromium based superalloys. The high strength and corrosion resistance properties make them well suited for adverse environments subjected to pressure and heat. Inconel 718 (50-55 wt\% Ni, 17-21 Cr, 13.25-24.6\% Fe, 4.75-5.50 Nb, 2.8-3.3 Mo, 0.65-1.15 Ti, 0.2-0.8 Al, <1.0 Co, <0.08 C) is a superalloy that can retain its mechanical properties at high temperature up to $650^{\circ} \mathrm{C}$ [5]. This precipitation hardenable material exhibits good creep and rupture strengths along with welding characteristics. It was reported that in an MAM process, repeated melting and fast cooling of the molten powders would form the dendrite solid solution $y$ phase, $\mathrm{NbC}$ niobium carbide, and the Laves phase [6-10]:

$$
\text { Liquid Inconel } 718 \rightarrow \gamma+\mathrm{NbC}+\text { Laves }
$$

Further heating of adjacent regions in L-PBF led to aging of the $\gamma$ phase to form $\delta$ precipitates, and other $\gamma$ ' and $\nu$ " precipitates. Compositions of the $\delta$ precipitate was reported as $\mathrm{Ni}_{3} \mathrm{Nb}$, that for the Laves was $(\mathrm{Ni}, \mathrm{Cr}, \mathrm{Fe})(\mathrm{Nb}$, $\mathrm{Mo}, \mathrm{Ti})$, and those for the $\gamma^{\prime}$ and $\gamma$ " precipitates were $\mathrm{Ni}_{3}(\mathrm{Al}, \mathrm{Ti})$ and $\mathrm{Ni}_{3} \mathrm{Nb}$ respectively $[10,11]$. The $\delta$ precipitates, typically needle shape of few-micron long, were formed primarily at grain boundaries and contained at least $6-8 \%$ $\mathrm{Nb}$. Both the $\gamma$ ' and $\gamma$ " precipitates, in nanometre scale, can be seen with transmission electron microscopy (TEM) and maybe visible with very high-resolution scanning electron microscopy (SEM). The Laves phases were the largest phase of all; contained at least $10 \% \mathrm{Nb}$, although a very large percentage of $35 \% \mathrm{Nb}$ in Laves was also reported [7]. The Laves phases can be dissolved by homogenizing at $1100^{\circ} \mathrm{C} / \mathrm{hr}$ before solution heat treating and aging to obtain the optimal mechanical properties of IN 718 [10]. Additional metal carbides were reported as $\mathrm{M}_{23} \mathrm{C}_{6}$ containing $\mathrm{Cr}$, $\mathrm{Mo}$, and $\mathrm{Nb}$. Both the $\mathrm{NbC}$ and $\mathrm{M}_{23} \mathrm{C}_{6}$ carbides were stable; a $\mathrm{NbC}$ phase, with significant $\mathrm{Nb}$ content, depleted $\mathrm{Nb}$ atoms around it and prevented formation of the finer $\gamma$ " precipitates [11].

Both volume and surface defects on MAM specimens had been reported in literature. Even though L-PBF IN 718 offered some advantages compared to subtractive methods, there were issues with pores, partially melted powder, shrinkage cavities, slags, and incomplete bonding between layers. Other studies [12,13] found spherical gas-filled pores trapped in the molten metal, balling phenomenon, partially melted powder particles that adhered on the top surface or at the boundary between deposited layers. These defects, caused by improper scanning speed and linear laser density, would act as detrimental stress raisers and finally led to early failure under fatigue conditions.

Many researchers had made efforts to improve the surface quality of L-PBF manufactured parts by studying the effects of processing parameters on surface morphologies, microstructures, and material properties of IN 718 . They found that surface integrity varied significantly at different laser energies and scanning speeds. By reducing the scanning speed from 300 to $100 \mathrm{~mm} / \mathrm{s}$, the positive results with nearly dense materials and relatively smooth surfaces were obtained $[3,14]$.

In another research, finish-turning of IN 718 with three different types of coated carbide tools in minimum quantity lubrication (MQL) were performed. Three types of coating selected in this study were the chemical vapor deposited (CVD) three-layers coating of $\mathrm{TiCN} / \mathrm{Al}_{2} \mathrm{O}_{3} / \mathrm{TiN}$, a physical vapor deposited (PVD) superlattice coating of TiN/AIN and a PVD monolayer coating of TiAIN. Cutting speeds were selected at 1.0 and $1.5 \mathrm{~m} / \mathrm{s}$. Amongst the three coatings there was always a trade-off between surface finish and the tool life. Machining with TiN/AIN coated tools in MQL provided the best surface finish amongst the three coatings but at the expenses of shorter tool life. The longest tool life was attained by using the $\mathrm{TiCN} / \mathrm{Al}_{2} \mathrm{O}_{3} / \mathrm{TiN}$ coated tools in wet-cutting but the surface finish was compromised [30].

Few researchers had applied ECP as the post-processing method to improve surface finish of IN 718. Combinations of perchloric, sulfuric, phosphoric, and acetic acids were suggested for ECP of IN 718 [15]. Phosphoric acid ensured a slow and uniform dissolution at the appropriate working conditions without significant adverse effects of corrosion or erosion, whereas sulfuric acid increased current density by causing the initial dissolution of the surface of workpiece. Neda et al. [31], proposed an innovative finishing technique combining chemical and abrasive flow polishing of 
interior surfaces of tubular IN 625 components for the aerospace industry. The results showed that by combining the chemical and abrasive flow polishing technique on the interiors surfaces, the surface roughness can be significantly improved from $17 \mu \mathrm{m}$ to $2.3 \mu \mathrm{m} R_{a}$; and the semi-welded particles that adhered on the surface can be completely removed.

Another study using ECP process to improve the surface finish of L-PBF IN 718 parts was performed. An anodic cylindrical part was position at centre of a cathodic cylindrical tank. The large 30-mm electrode gap was filled with stirred electrolyte (20\% sulfuric acid and methanol). Current density of $50 \mathrm{~A} / \mathrm{dm}^{2}$ was applied between electrodes for different intervals of 1-5 minutes. At optimal condition, the resulted surface roughness $R_{a}$ was reduced to 3.66 $\mu \mathrm{m}$ from $6.05 \mu \mathrm{m}$. Nano hardness of the polished samples, however, was reduced due to dissolving of the strengthening precipitates during the etching/polishing process. The needle shaped $\delta$-phase and carbide particles appeared in the grain boundaries after long polishing time of 5 minutes [17].

Surface finish of electrochemically drilled holes in conventionally manufactured wrought IN 718 was performed. The $\varnothing 0.5 \mathrm{~mm}$ brass electrodes were used as the drilling tool. The authors varied the input variables (pulsed voltage, duty cycle, electrolyte concentration and types -- $\mathrm{NaCl}_{\text {or }} \mathrm{NaNO}_{3}-$ and the electrode feed rate). Surface finish inside an $\varnothing 0.5 \mathrm{~mm}$ hole was measured with a non-contact probe. The study concluded that $\mathrm{NaCl}$ should be used for high drilling rate, while $\mathrm{NaNO}_{3}$ should be used for fine surface finish. A surface finish range of 0.535-3.930 $\mu \mathrm{m} R_{a}$ was reported [18].

The performance of ECP can also be enhanced by switching the applied direct current to pulsed current. The additional off-time in pulsed current allowed effective flushing of debris/ions and refreshing of new electrolyte to the anodic surface [19-23]. When combining with ultrasonic vibration, the cavitation effect led to effective flushing and improved surface finish of ECP parts [24]. Electrochemical grinding was used as finishing process for IN 718 [25]. High material removal rate could be obtained with brazed diamond wheel, high applied-voltage, feed rate and electrolyte temperature; however, the resulted surface finish was not included in the report.

\section{EXPERIMENTS}

\subsection{Sample Preparation}

Both the L-PBF and extruded IN 718 samples were prepared for ECP process.

- The L-PBF parts were laser printed to $15 \times 20 \times 5 \mathrm{~mm}$ on a Renishaw AM250 system. The $15 \times 20 \mathrm{~mm}$ base surface was parallel to the scanning $x-y$ plane while the $5 \mathrm{~mm}$ thickness was along the building $z$-direction. The average diameter of IN 718 powder was $50 \mu \mathrm{m}$ and the powder was fused together using a YAC laser beam at $160 \mathrm{~W}$ power with a hatching distance of $110 \mu \mathrm{m}$ in argon gas. The stripe scanning strategy was adopted for the manufacturing of these samples.

- The extruded samples were cut from an annealed $\varnothing 19.1 \mathrm{~mm}$ bar using Wire-type Electrical Discharged Machining (Wire EDM) method. A sample was cut to the same size of $15 \times 20 \times 5 \mathrm{~mm}$ with the $15 \times 20 \mathrm{~mm}$ surface is perpendicular to the bar axial direction.

Due to inconsistent surface profiles of MAM and extruded surfaces, each specimen surface was normalized by handgrinding with a fresh 180-grit SiC paper in a uniform direction to achieve an even surface. The sanded samples were then cleaned ultrasonically for 5 minutes in isopropyl alcohol to remove any debris and contaminants before ECP.

\subsection{Experimental Set-up}

The anodic workpiece (IN 718) was then clamped in the ESMA ECP system with a sanded direction in vertical direction. A cathodic titanium electrode with hemispherical end was used to minimize orientation error. The titanium electrode was mounted on a Teflon holder that electrically insulated it from the motor. A multimeter was used to detect the electrical contact of both clean and dried electrode/workpiece surfaces, after which the Velmex bislide system with $5 \mu \mathrm{m}$ repeatability was used to move the electrode and position it $0.5 \mathrm{~mm}$ away from the specimen surface (Fig. 1). A minimum of at least 4 trials were performed to verify the repeatability of electrical contact of the two electrodes and the interelectrode gap.

A full factorial experiment was conducted based on three ECP input parameters (current density, polishing time, and duty cycle) at three different levels. The numerical values of these levels were selected after completion of preliminary experiments. The duty cycles of 25,50 , and $75 \%$ were chosen to study the effect of off-time from current pulses. A longer off-time (low duty cycle) would allow more flushing time but reducing the polishing rate. Thus, a total of 27 experiments with two replicates were conducted to polish the L-PBF and extruded IN 718 samples.

A commercial and proprietary mixture of phosphoric and sulphuric acids was used. It consisted of a high percentage of phosphoric acid about $40-80 \%$ and sulphuric acid with $5-35 \%$ by weight. Although this electrolyte can be used up to $65^{\circ} \mathrm{C}\left(150^{\circ} \mathrm{F}\right)$, it was used at room temperature in this study, since a high testing temperature would lead to aggressive chemical reactions suitable for machining but not for polishing. A fresh electrolyte was used for every set of 27 experiments. Table 1 lists all variables, constants, and equipment in this study while Table 2 tabulates different samples and respective ECP parameters. After polishing, a workpiece with remnant electrolyte was first rinsed in running tap water, and then dried completely with compressed air.

A schematic of polished specimen is shown in Figure 2. After ECP'ed, rinsed, and dried, the surface of a specimen was studied in the rectangular zone of $3 \times 3 \mathrm{~mm}^{2}$. Both the Olympus STM6 optical microscope and Vegas scanning electron microscope (SEM) were used for microstructure study. An Energy Dispersive Spectroscopy (EDS) system, 
integrated with the Vegas SEM, was utilized to identify different phases in the microstructure of polished samples. Surface roughness was measured with the Alicona G4 IF profiler within a square zone of $1 \times 1 \mathrm{~mm}$ for area surface finish $S_{a}$ and a $1 \mathrm{~mm}$ length for line surface finish $R_{a}$. Surface evaluation was repeated four times at each location in both directions, parallel and perpendicular to the sanding marks. Figure 2 defines different zones and the coordinate system. The $y$-axis was chosen to be parallel to sanding marks while the $x$-axis was perpendicular to the sanding direction.

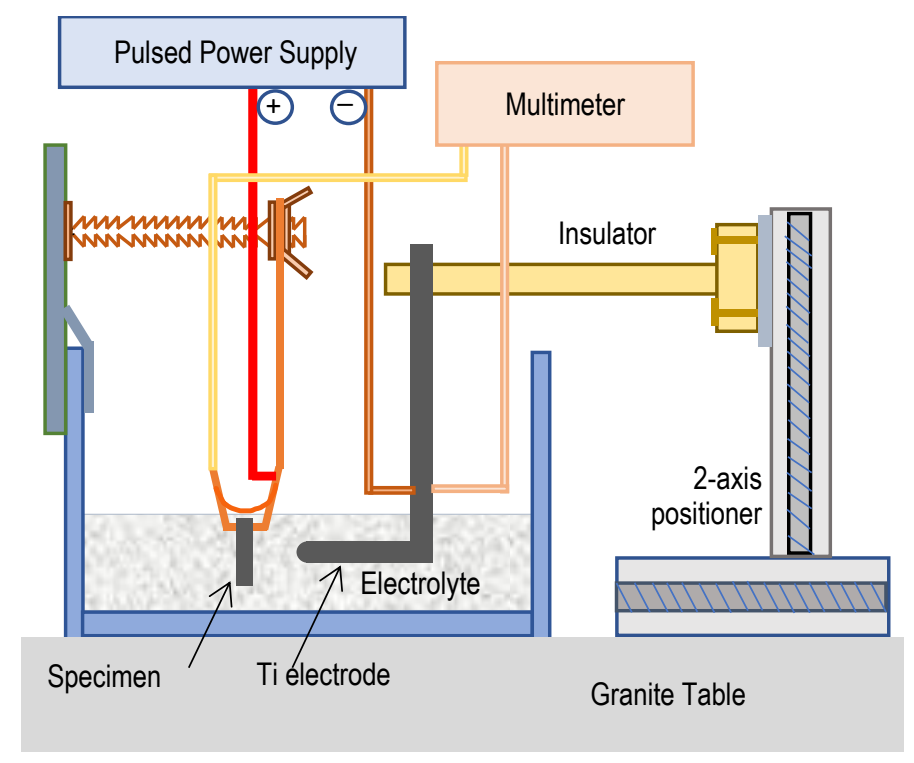

Figure 1: Schematic of experimental set-up

Table 1: Experiment Design

\begin{tabular}{ll}
\hline Variables & Values \\
\hline Current density $\left(\mathrm{A} / \mathrm{mm}^{2}\right)$ & $0.2,0.7,1.2$ \\
Duty cycle (\%) & $25,50,75$ \\
Polishing time (s) & $90,180,270$ \\
\hline Constants and dependent variables \\
\hline On-time (ms) & $10,20,30$ \\
Peak current (A) & $1.0,3.5,6.0$ \\
Interelectrode gap (mm) & 0.5 \\
Electrolyte & Commercial acid-based, EP 2000 \\
Electrode & $\varnothing 2.5$ mm commercially pure titanium \\
\hline Equipment & Model \\
\hline ECP cell & ESMA model E1085-1S \\
Power supply & Dynatronix (CRS-LFP(R)) \\
Multimeter & Tenma 72-6202 \\
3D optical profiler & Alicona IF \\
Positioner & Velmex bislide MN10 \\
Optical microscope & Olympus STM6 \\
Scanning electron microscope & VEGA3 Tescan \\
\hline
\end{tabular}


Table 2: Factorial Design

\begin{tabular}{|c|c|c|c|c|}
\hline $\begin{array}{l}\text { Sample } \\
\text { Number }\end{array}$ & Current (A) & $\begin{array}{c}\text { Current } \\
\text { density } \\
\left(\mathrm{A} / \mathrm{mm}^{2}\right)\end{array}$ & Time (sec) & $\begin{array}{c}\text { Duty Cycle } \\
(\%)\end{array}$ \\
\hline 1 & 1 & 0.2 & \multirow{3}{*}{90} & \multirow{9}{*}{25} \\
\hline 2 & 3.5 & 0.7 & & \\
\hline 3 & 6 & 1.2 & & \\
\hline 4 & 1 & 0.2 & \multirow{3}{*}{180} & \\
\hline 5 & 3.5 & 0.7 & & \\
\hline 6 & 6 & 1.2 & & \\
\hline 7 & 1 & 0.2 & \multirow{3}{*}{270} & \\
\hline 8 & 3.5 & 0.7 & & \\
\hline 9 & 6 & 1.2 & & \\
\hline 10 & 1 & 0.2 & \multirow{3}{*}{90} & \multirow{9}{*}{50} \\
\hline 11 & 3.5 & 0.7 & & \\
\hline 12 & 6 & 1.2 & & \\
\hline 13 & 1 & 0.2 & \multirow{3}{*}{180} & \\
\hline 14 & 3.5 & 0.7 & & \\
\hline 15 & 6 & 1.2 & & \\
\hline 16 & 1 & 0.2 & \multirow{3}{*}{270} & \\
\hline 17 & 3.5 & 0.7 & & \\
\hline 18 & 6 & 1.2 & & \\
\hline 19 & 1 & 0.2 & \multirow{3}{*}{90} & \multirow{9}{*}{75} \\
\hline 20 & 3.5 & 0.7 & & \\
\hline 21 & 6 & 1.2 & & \\
\hline 22 & 1 & 0.2 & \multirow{3}{*}{180} & \\
\hline 23 & 3.5 & 0.7 & & \\
\hline 24 & 6 & 1.2 & & \\
\hline 25 & 1 & 0.2 & \multirow{3}{*}{270} & \\
\hline 26 & 3.5 & 0.7 & & \\
\hline 27 & 6 & 1.2 & & \\
\hline
\end{tabular}

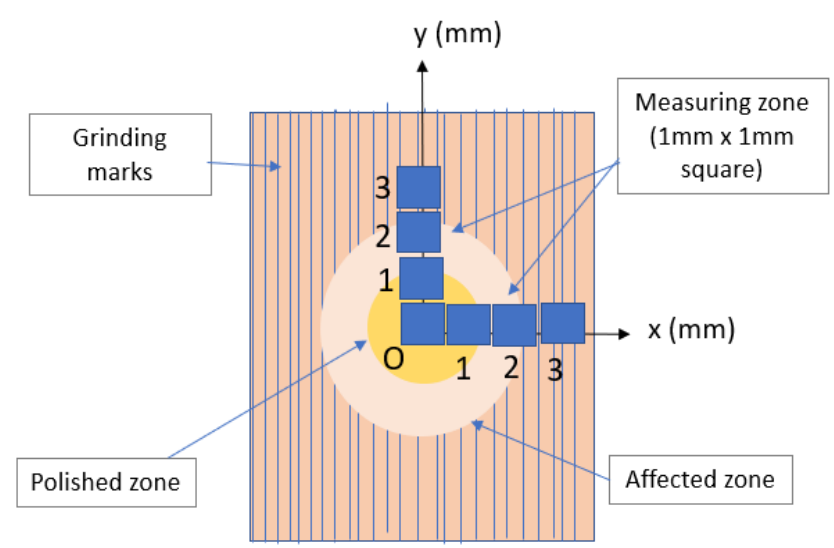

Figure 2: Schematic of polished zone and surrounding area 


\section{RESULTS AND DISCUSSIONS \\ 3.1 Surface Finish}

The average surface finish of as-printed samples on $x y$-plane was measured to be 17-20 $\mu \mathrm{m} S a$, the measurement was even rougher in the building z-direction due to layer mismatching and partially welded powder particle on the surface (Fig. 4a). Alternate layers with different microstructures are shown on $x-y$ plane (Fig. 4b), additional defects like shrinkage cavities, microcracks, slags were also observed; therefore, each sample was normalized by sanding for a uniform surface before polishing (Fig. 5a).

ECP conditions: Current density $\left(\mathrm{A} / \mathrm{mm}^{2}\right)$, Polishing time $(\mathrm{s})$, and Duty Cycle (\%) respectively. refers to Figure 5 shows the success of ECP when all the sanding marks were completely removed. The repeatability of ECP system and the uniformity of ECP polished surfaces were confirmed:

- Repeatability. A set of 15 extruded samples were electropolished in a random order to check the repeatability of the ECP system. The average error was within $\pm 7 \%$ as shown in Table 3.

- Isotropy. Table 4 and Fig. 6 show the uniformity of ECP polishing. The line surface roughness $R_{a}$ values, measured in both perpendicular and parallel to grinding marks, were practically the same since the data were statistically indifference. This implies (i) a grinding mark was polished completely as confirmed with microscopic observation, and (ii) the electrical field around the titanium electrode was uniform and symmetric so that ions are uniformly removed around the electrode; however, the distance from electrode tip to a specific location affected the material removal rate (Fig. 7). The material was polished more at location just below the electrode, and the effect diminished away from the electrode. A larger electrode or control motion of electrode would solve this issue.

Table 5 shows the difference in surface finish of L-PBF and extruded IN 718 parts. Submicron surface finish was achieved in the polished zones; the process was repeated twice for each condition and the measured results -the average of four random measurements- were repeated within $\pm 8 \%$.

As expected, the duty cycle of $75 \%$ yielded better results for both the MAM and extruded samples. At this optimal condition, the longer on-time allowed more material to be removed yet left sufficient off-time for flushing debris and replenishing of fresh electrolyte to the polished surface. The vertical position of polished anode also facilitated the removal of debris during polishing; an anodic workpiece in horizontal position would accumulate fine debris, especially the nonconductive contaminants, at the polishing zone and interfere with ion transport mechanism.

Figures $8 \mathrm{a}-\mathrm{c}$ below compare the surface finish between the L-PBF and extruded specimens at different polishing durations at each duty cycle of $25 \%, 50 \%$ and $75 \%$ respectively.

- $\quad$ Polishing of L-PBF samples. At every duty cycle, 90 seconds of polishing duration produced the best surface finish, but the roughness increased after longer polishing time from 90 to 270 seconds. The issues were with microstructural defects such as pores and nonconductive intermetallic phases like carbide or Laves. The ECP process would remove the conductive matrix according to Faraday law, but would not affect the nonconductive "contaminants" in the materials. During the ECP process, ions from the conductive matrix were removed and exposed more nonconductive defects on the polished surface, thus degrading the surface texture. The best surface finish for L-PBF samples was $0.28 \mu \mathrm{m}$ after ECP at $0.7 \mathrm{~A} / \mathrm{mm}^{2}$ current density, 90 s polishing time, and $75 \%$ duty cycle.

- Polishing of extruded samples. The microstructure of extruded samples was more uniform. Polishing of extruded samples after 270 s gives the best surface finish at every duty cycle.

The reaction equation (1) predicts significant microstructural changes in MAM. Such metallurgical reaction happened regardless of different AM processes that utilize either laser, electron beam, or plasma arc to deposit successive layers of metal beads. The fast heating and rapid cooling of each layer formed the brittle intermetallic compound Laves phases with combination of ( $\mathrm{Ni}, \mathrm{Cr}, \mathrm{Fe})(\mathrm{Nb}, \mathrm{Mo}, \mathrm{Ti})$. Figures $4 \mathrm{~b}-\mathrm{c}$ shows alternative layers of IN 718 after melted, solidified, and reheated again when a laser scanned and melted adjacent beads. Contamination of IN 718 powder after repeated PBF cycles also contribute to irregularities in the microstructure of samples fabricated by L-PBF process.

In contrast, the hot extruded materials are commonly performed at temperature approximately half of the absolute melting temperature of those metals. The metallurgical reaction (1) does not apply to IN 718 at the relatively low temperature during hot extrusion, therefore, we would expect a more uniform microstructure with no porosity in extruded samples. The polishing results by ECP can be further explained when examining the microstructure of the polished samples. 

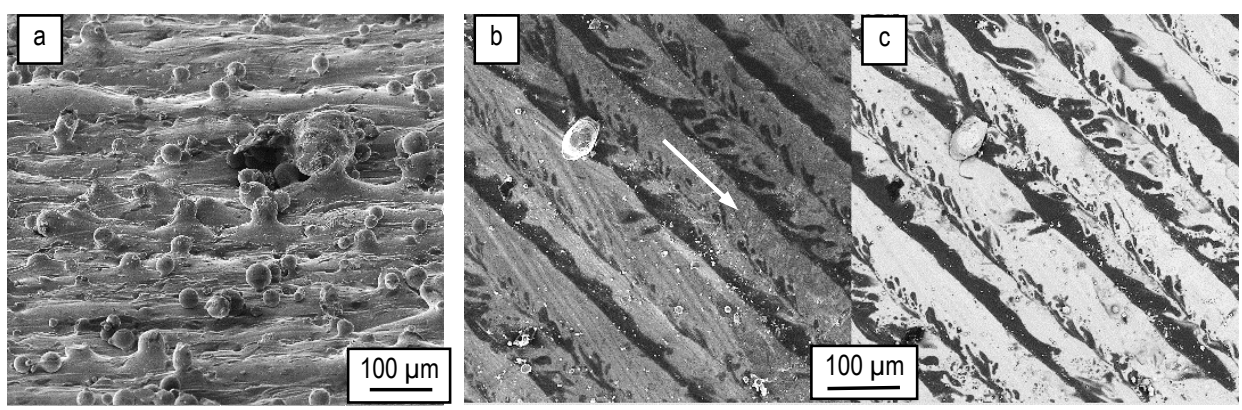

Figure 4: Surface profile of L-PBF Inconel 718: (a) Partially welded powder particles on xz-plane, (b) secondary electron image of $x-y$ plane, and (c) back-scattered electron image on $x-y$ plane. The arrow in (b) indicates the laser scanning direction.
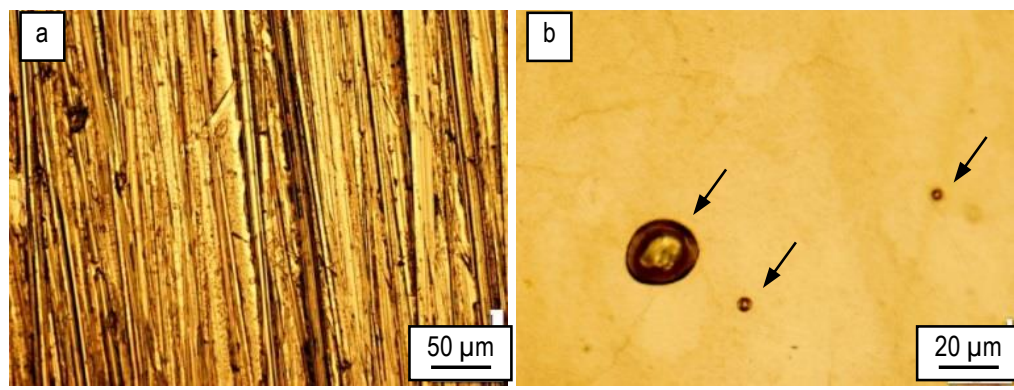

Figure 5: Optical image of (a) sanded L-PBF Inconel 718, and (b) polished zone after $0.70 \mathrm{~A} / \mathrm{mm}^{2}, 90 \mathrm{~s}, 50 \%$ duty cycle. The arrows point to different pores on the polished surface.

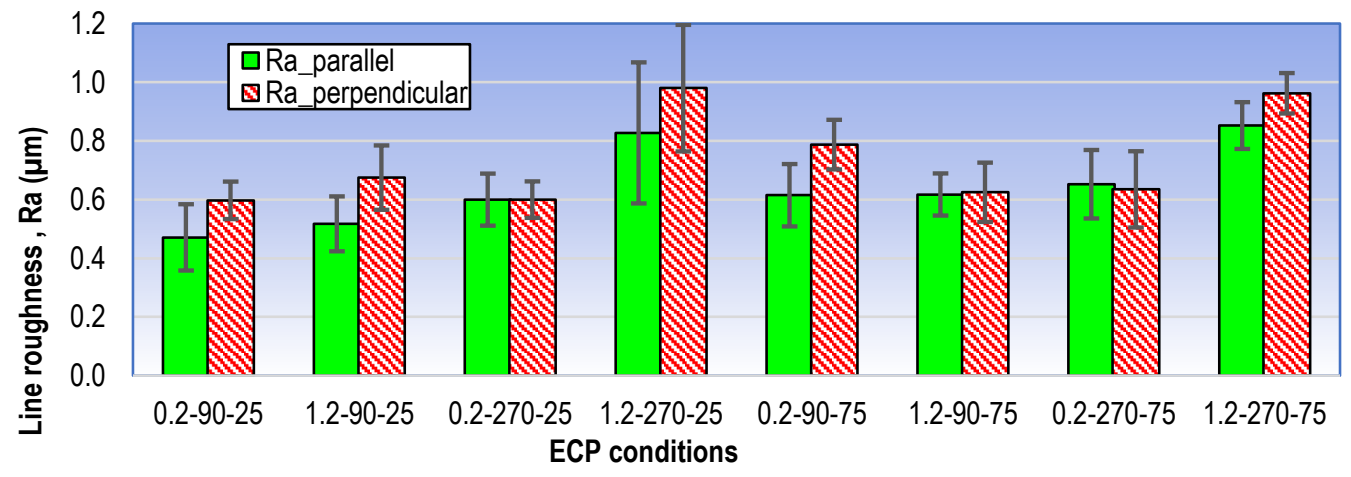

Figure 6: Surface finish of measuring in direction relative to grinding marks.

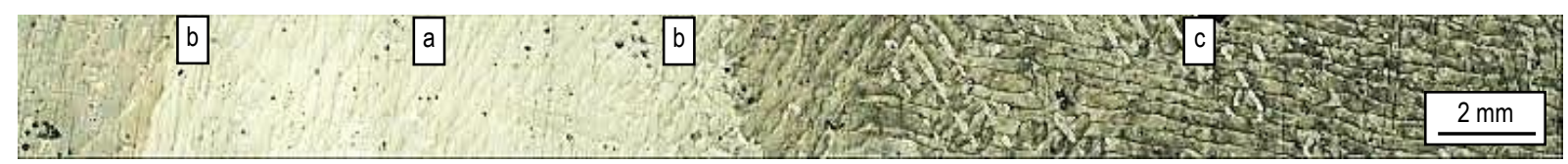

Figure 7: Effect of distance from electrode on polishing results showing (a) polished zone directly below the electrode, (b) transitional zone, and (c) unpolished zone. L-PBF specimen after $0.2 \mathrm{~A} / \mathrm{mm}^{2}, 180 \mathrm{~s}, 50 \%$ duty cycle. 

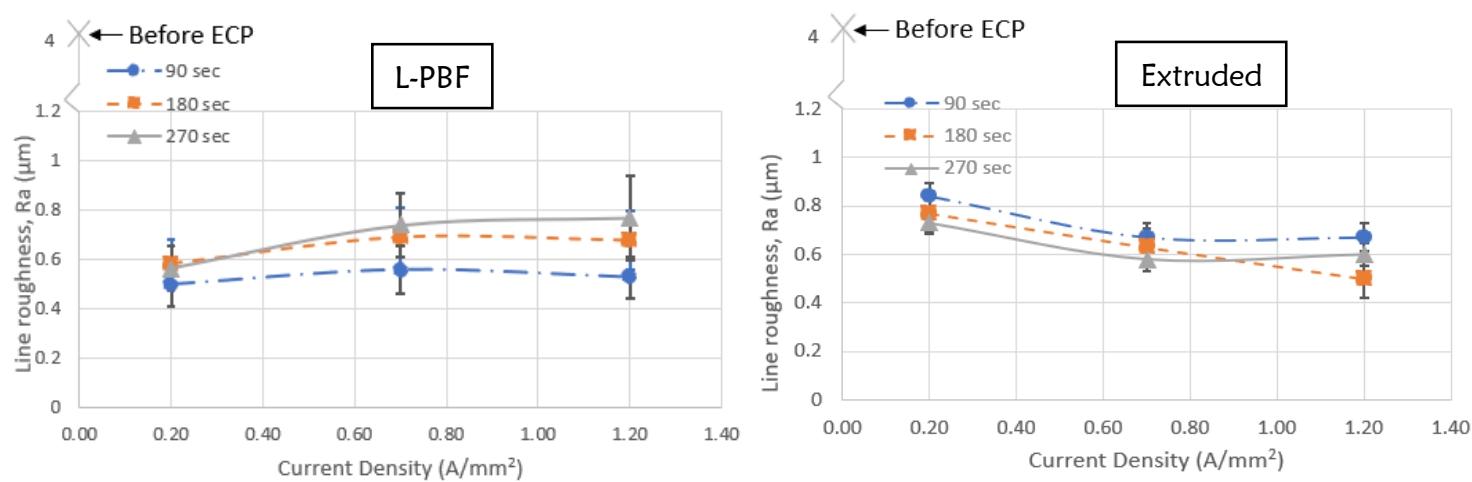

(a)
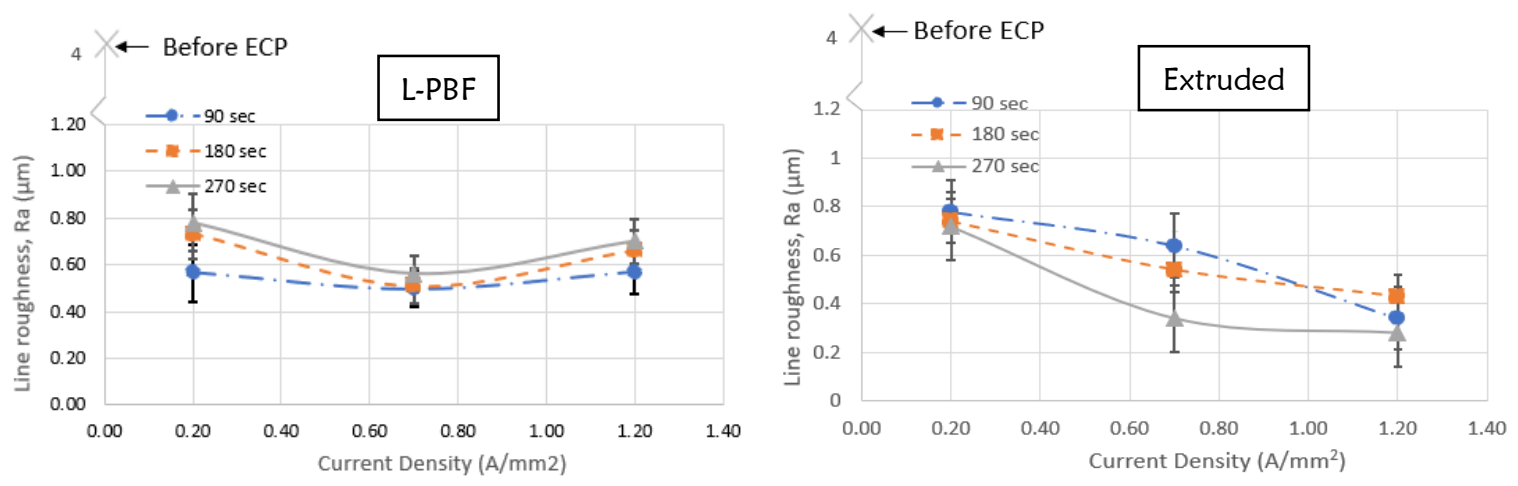

(b)
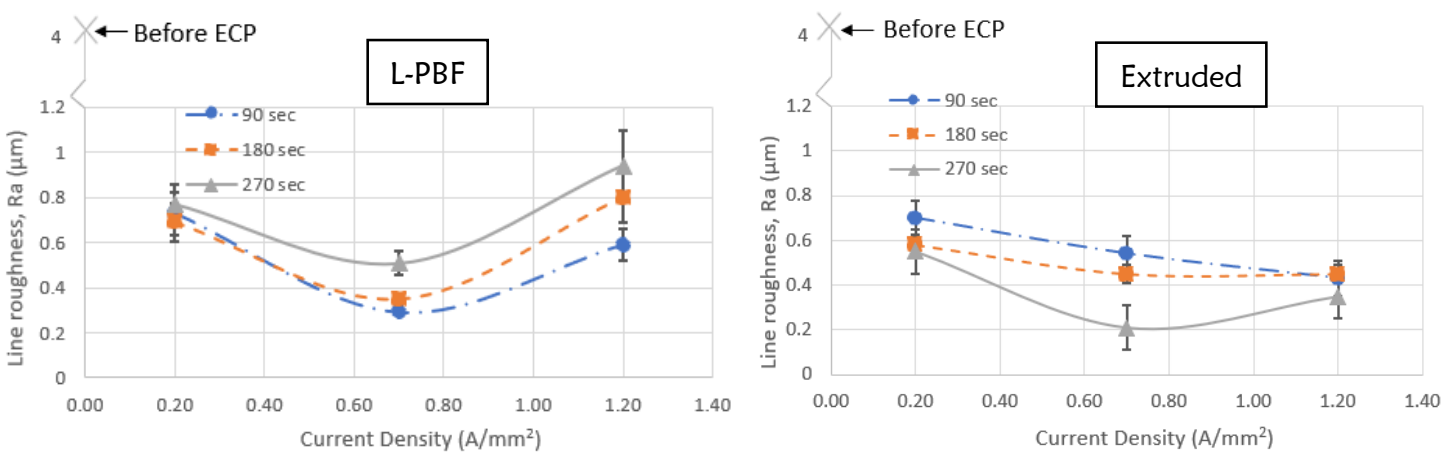

(c)

Figure 8: Comparison of roughness at polished zone of $A M$ and wrought specimens. ECP at $25 \mathrm{~Hz}$ at (a) $25 \%$, (b) $50 \%$, and (c) $75 \%$ duty cycle. Average of 4 data points. 
Table 3: Repeatability of ECP results

\begin{tabular}{|c|c|c|c|c|c|c|}
\hline Sample number & Current density $\left(\mathrm{A} / \mathrm{mm}^{2}\right)$ & $\begin{array}{l}\text { Time } \\
(\mathrm{sec})\end{array}$ & $\begin{array}{c}\text { Duty cycle } \\
(\%)\end{array}$ & $\begin{array}{c}\text { Original Ra } \\
(\mu \mathrm{m})\end{array}$ & $\begin{array}{c}\text { Repeated } \\
\operatorname{Ra}(\mu \mathrm{m}) \\
\end{array}$ & $\begin{array}{c}\text { Error } \\
(\%) \\
\end{array}$ \\
\hline 1 & \multirow{4}{*}{0.20} & 180 & 25 & 0.77 & 0.75 & $-3 \%$ \\
\hline 2 & & 180 & 75 & 0.58 & 0.55 & $-5 \%$ \\
\hline 3 & & 270 & 25 & 0.73 & 0.69 & $-5 \%$ \\
\hline 4 & & 270 & 75 & 0.55 & 0.53 & $-4 \%$ \\
\hline 5 & \multirow{6}{*}{0.70} & 90 & 75 & 0.54 & 0.58 & $7 \%$ \\
\hline 6 & & 180 & 75 & 0.45 & 0.42 & $-7 \%$ \\
\hline 7 & & 270 & 75 & 0.21 & 0.2 & $-5 \%$ \\
\hline 8 & & 90 & 25 & 0.67 & 0.69 & $3 \%$ \\
\hline 9 & & 180 & 25 & 0.63 & 0.65 & $3 \%$ \\
\hline 10 & & 270 & 25 & 0.58 & 0.566 & $-2 \%$ \\
\hline 11 & \multirow{5}{*}{1.20} & 90 & 25 & 0.67 & 0.695 & $4 \%$ \\
\hline 12 & & 90 & 75 & 0.43 & 0.46 & $7 \%$ \\
\hline 13 & & 180 & 25 & 0.5 & 0.53 & $6 \%$ \\
\hline 14 & & 180 & 75 & 0.45 & 0.465 & $3 \%$ \\
\hline 15 & & 270 & 25 & 0.6 & 0.58 & $-3 \%$ \\
\hline
\end{tabular}

Table 4: Data for parallel and perpendicular roughness comparison

\begin{tabular}{|c|c|c|c|c|c|c|c|c|c|c|}
\hline \multirow{2}{*}{$\begin{array}{l}\text { Polishing } \\
\text { condition * }\end{array}$} & \multicolumn{4}{|c|}{ Parallel } & \multirow{2}{*}{$\begin{array}{c}\sigma \text { for } \\
\operatorname{Ra}(1-4)\end{array}$} & \multicolumn{4}{|c|}{ Perpendicular } & \multirow{2}{*}{$\begin{array}{c}\sigma \text { for } \\
\operatorname{Ra}(5-8)\end{array}$} \\
\hline & $\begin{array}{c}\text { Ral } \\
(\mu \mathrm{m})\end{array}$ & $\begin{array}{l}\mathrm{Ra} 2 \\
(\mu \mathrm{m})\end{array}$ & $\begin{array}{l}\mathrm{Ra3} \\
(\mu \mathrm{m})\end{array}$ & $\begin{array}{l}\mathrm{Ra} 4 \\
(\mu \mathrm{m})\end{array}$ & & $\begin{array}{l}\mathrm{Ra5} \\
(\mu \mathrm{m})\end{array}$ & $\begin{array}{c}\mathrm{Ra6} \\
(\mu \mathrm{m})\end{array}$ & $\begin{array}{l}\mathrm{Ra7} \\
(\mu \mathrm{m})\end{array}$ & $\begin{array}{l}\mathrm{Ra} 8 \\
(\mu \mathrm{m})\end{array}$ & \\
\hline $0.2-90-25$ & 0.425 & 0.64 & 0.4 & 0.42 & 0.11 & 0.57 & 0.53 & 0.61 & 0.55 & 0.06 \\
\hline $1.2-90-25$ & 0.61 & 0.58 & 0.48 & 0.47 & 0.09 & 0.62 & 0.58 & 0.63 & 0.59 & 0.11 \\
\hline $0.2-270-25$ & 0.57 & 0.65 & 0.69 & 0.49 & 0.09 & 0.67 & 0.63 & 0.57 & 0.53 & 0.06 \\
\hline $1.2-270-25$ & 1.18 & 0.66 & 0.78 & 0.99 & 0.24 & 0.97 & 0.93 & 1.05 & 0.61 & 0.22 \\
\hline $0.2-90-75$ & 0.73 & 0.67 & 0.49 & 0.57 & 0.11 & 0.74 & 0.7 & 0.82 & 0.71 & 0.08 \\
\hline $1.2-90-75$ & 0.59 & 0.53 & 0.66 & 0.69 & 0.07 & 0.65 & 0.59 & 0.51 & 0.75 & 0.10 \\
\hline $0.2-270-75$ & 0.77 & 0.5 & 0.71 & 0.63 & 0.12 & 0.69 & 0.65 & 0.45 & 0.75 & 0.13 \\
\hline $1.2-270-75$ & 0.94 & 0.84 & 0.78 & 0.81 & 0.08 & 0.93 & 0.89 & 0.94 & 0.85 & 0.07 \\
\hline
\end{tabular}

* The three numbers refer to Current density $\left(\mathrm{A} / \mathrm{mm}^{2}\right)$, Polishing time (s), and Duty Cycle (\%) respectively. 
Table 5: ECP results of L-PBF and extruded samples

\begin{tabular}{|c|c|c|c|c|c|}
\hline \multirow{2}{*}{ Sample number } & \multirow{2}{*}{ Current density $\left(\mathrm{A} / \mathrm{mm}^{2}\right)$} & \multirow{2}{*}{ Time (sec) } & \multirow{2}{*}{ Duty cycle (\%) } & \multicolumn{2}{|c|}{ Surface finish, $\operatorname{Ra}(\mu \mathrm{m})$} \\
\hline & & & & L-PBF & Extruded \\
\hline 1 & \multirow{4}{*}{0.2} & 180 & 25 & 0.77 & 0.51 \\
\hline 2 & & 180 & 75 & 0.58 & 0.67 \\
\hline 3 & & 270 & 25 & 0.73 & 0.49 \\
\hline 4 & & 270 & 75 & 0.55 & 0.35 \\
\hline 5 & \multirow{6}{*}{0.7} & 90 & 75 & 0.54 & 0.75 \\
\hline 6 & & 180 & 75 & 0.45 & 0.30 \\
\hline 7 & & 270 & 75 & 0.21 & 0.24 \\
\hline 8 & & 90 & 25 & 0.67 & 0.45 \\
\hline 9 & & 180 & 25 & 0.63 & 0.82 \\
\hline 10 & & 270 & 25 & 0.58 & 0.60 \\
\hline 11 & \multirow{5}{*}{1.2} & 90 & 25 & 0.67 & 0.49 \\
\hline 12 & & 90 & 75 & 0.43 & 0.31 \\
\hline 13 & & 180 & 25 & 0.5 & 1.11 \\
\hline 14 & & 180 & 75 & 0.45 & 0.32 \\
\hline 15 & & 270 & 25 & 0.6 & 0.5 \\
\hline
\end{tabular}

\subsection{Microstructures}

Both samples -extruded and additively manufactured-- were polished at the same ECP parameters for comparison. The extruded and annealed specimens had a uniform microstructure consisted of the matrix and $\delta$ precipitates along the grain boundaries and did not exhibit any obvious material defects (Fig. 9a). Aghajani et al. [11] reported that ceramic carbides can be formed in the microstructure of IN 718. The niobium carbides $(\mathrm{NbC})$ combined and used niobium atoms from the surrounding matrix. Defects in IN 718 affected the polishing results due to:

- Inclusions. Both metallic carbide $\mathrm{M}_{23} \mathrm{C}_{6}$, and niobium carbide $\mathrm{NbC}$ are seen in the microstructure. The metallic carbides were embedded into the surrounding matrix (Fig. 10a), but the $\mathrm{NbC}$ inclusions contained niobium atoms, therefore, the etching rate of niobium depleted zone and the matrix of IN 718 should be different. Scanning electron microscopic observation shows NbC particles surrounded by dark zones that implied materials with different chemical compositions, or the different topography after electro-chemical etching (Fig. 10b). In addition to the carbide phases, the segregated niobium also was shared by precipitates such as $\delta$ (Incoherent $\left.-\mathrm{Ni}_{3} \mathrm{Nb}\right), \gamma^{\prime}\left(\mathrm{Ni}_{3} \mathrm{Al}\right), \gamma^{\prime \prime}\left(\mathrm{Ni}{ }_{3} \mathrm{Nb}\right)$, and Laves phases $\left((\mathrm{Ni}, \mathrm{Cr}, \mathrm{Fe})_{2}(\mathrm{Nb}, \mathrm{Mo}, \mathrm{Ti})\right)$. The precipitates were dissolved in the etching solution due to their small sizes, but the larger and nonconductive carbides and Laves particles had much lower etching rates as compared to that of the matrix.

- Voids. There was no porosity in extruded samples, but voids and smaller spherical pores were seen in the L-PBF samples. The geometry of voids/pores on polished surface degraded the surface roughness of MAM samples. Common pores and voids may have tiny cracks in grain boundaries (Fig. 11b); materials at such irregular feature with sharper edges were removed at a faster rate due to higher current density in ECP. A crack within a pore, or between 3D-printed layers was enlarged after ECP as shown in Figs. 11a and 12a.

- Strain-induced etching. Microlevel strains were induced in the matrix by precipitates, inclusions, temperature difference, or grinding/machining actions. Although in minute scales, such plastic train was significant enough to (i) lower the activation energy for electrochemical reaction, (ii) accelerate the local material removal rate, and (iii) degrade the overall surface quality of ECP samples. Fig. $12 \mathrm{~b}$ shows craters in the material matrix with inclusions (labelled \#2) at the centre; but no surrounding craters with other inclusions (labelled \#1). Perhaps these inclusions were different in compositions and had different thermal expansion coefficients with that from the matrix, thus imparted different micro-strain levels at the corresponding circumferences.

Figures $13 \mathrm{a}-\mathrm{c}$ show the evolution of a L-PBF surface. The vertical grinding marks on as-printed samples (Fig. 13a) were gradually removed (Fig. 13b) until the final step (Fig. 13c). However, the plastic strain underneath a grinding mark was still present in the optical image and shown as residual grinding mark in 
Fig. 13c. The residual marks, that were not visible in scanning electron microscopy, indicated nonuniform electrochemical reaction rates. Perhaps such residual marks can be quantitatively detected by atomic force microscopy. Grain boundaries (Fig. 13c) and scanning laser paths (Fig. 13b) were also visible due to preferred and different etching rates due to high strain energy at grain boundaries and boundaries of laser melted seams.

- Electrical conductivity. The ECP process required control movement of ions and electrons to effectively remove and polish an anodic workpiece in atomic scale. Nonconductive phases such as precipitates, voids/pores, cracks, inclusions, ceramic particles, slags/contaminants were not affected by ECP. Even conductive phases with different electrical conductivities in an inhomogeneous matrix would have different etching rates and affect the surface finish of polished samples.

Submicron surface finish on both extruded and L-PBF materials was achieved in this study; however, the microstructure of each material contributed to final surface finish. Referring to Fig. 8 that compares surface finish of two materials, the L-PBF samples had the lowest surface finish of $0.25 \mu \mathrm{m} R_{a}$ at $0.7 \mathrm{~A} / \mathrm{mm}^{2}, 75 \%$ duty cycle after 90 s. Longer polishing time and higher current density worsened the surface finish since more defects would be exposed after removing the matrix materials. In contrast, due to the more homogeneous microstructure and less defects, the surface of extruded samples can be further improved after longer time or by applying a higher current density.

Post processing techniques can be applied to the L-PBF material to improve its microstructure before polishing. Pores can be reduced by modifying the scanning strategies [27], but it might be more cost effective when hot-isostatic pressing the bulk number of L-PBF parts. Since Laves phases and pores can be eliminated by homogenizing and hotisostatic pressing $[6,8,10,28,29]$, these post processes could be applied before ECP to achieve a better surface finish.
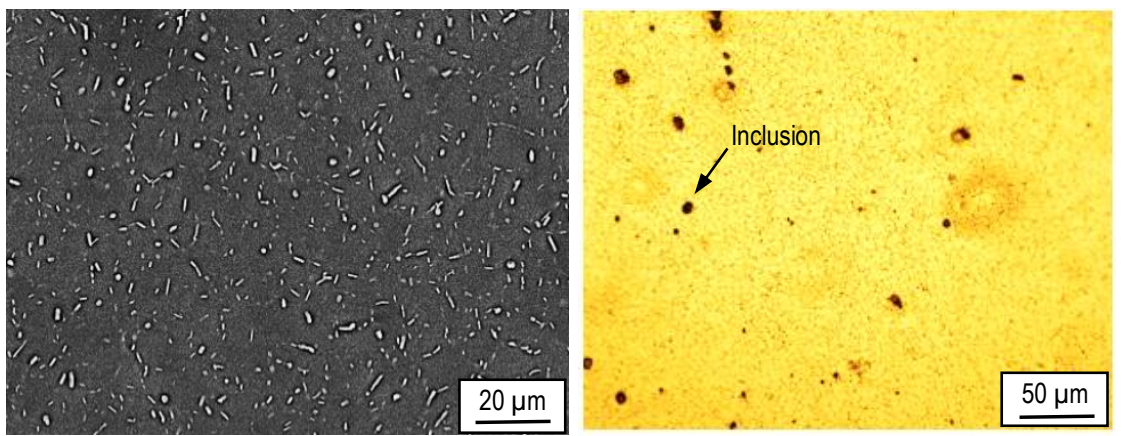

Figure 9: (a) SEM image of extruded sample, viewing along the extruding direction. The needle shape $\delta$ phases are visible along grain boundaries. ECP at $0.7 \mathrm{~A} / \mathrm{mm}^{2}, 270 \mathrm{~s}, 75 \%$ duty cycle; and (b) Optical image of extruded sample. $\mathrm{ECP}$ at $0.7 \mathrm{~A} / \mathrm{mm}^{2}, 270 \mathrm{~s}, 50 \%$ duty cycle.
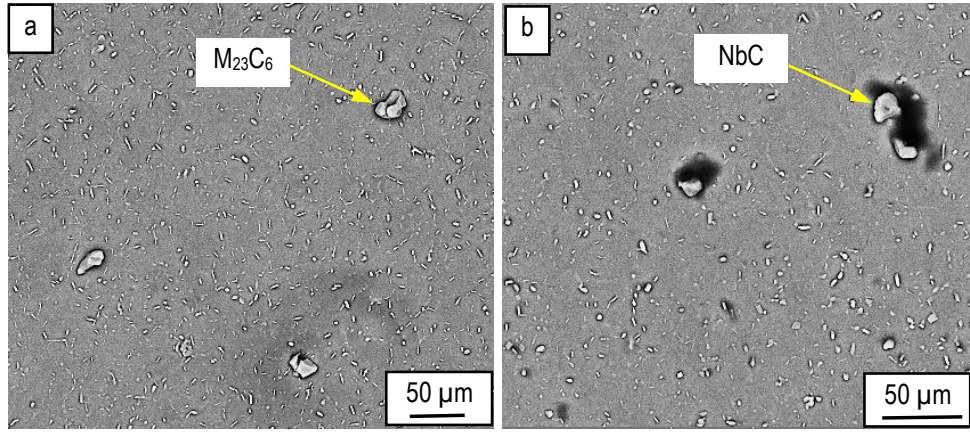

Figure 10: Inclusions in extruded sample (a) Metallic carbide, and (b) Niobium carbide with depleted surrounding. ECP at $0.7 \mathrm{~A} / \mathrm{mm}^{2}, 270 \mathrm{~s}, 75 \%$ duty cycle. 

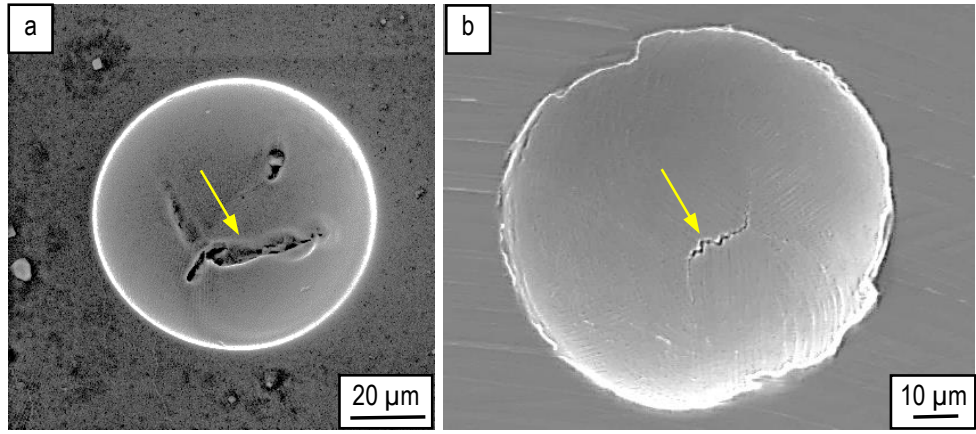

Figure 11: Enhanced defects of L-PBF samples; (a) Enlarged crack within a pore after ECP at $0.7 \mathrm{~A} / \mathrm{mm}^{2}, 180 \mathrm{~s}$ and $75 \%$ duty cycle, and (b) Typical crack within a pore before ECP.
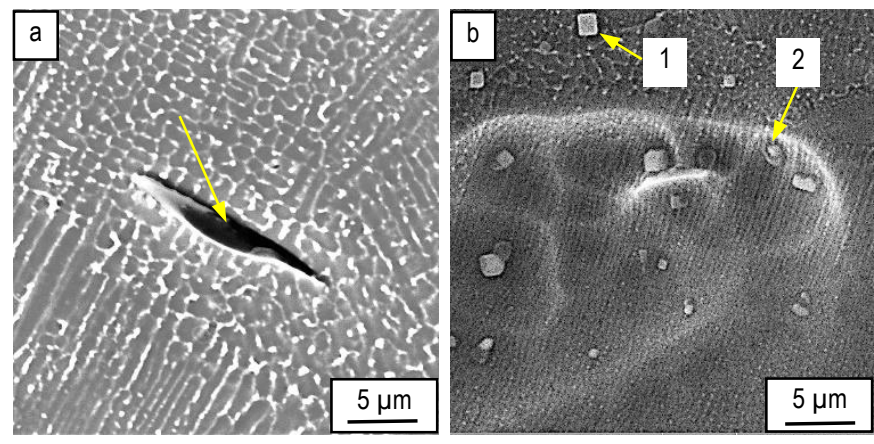

Figure 12: Enhanced defects after ECP of L-PBF samples; (a) Crack after ECP at $1.2 \mathrm{~A} / \mathrm{mm}^{2}, 270$ s and $50 \%$ duty cycle, (b) Differential etching rates around different inclusions. ECP at $0.7 \mathrm{~A} / \mathrm{mm}^{2}, 180 \mathrm{~s}$ and $75 \%$ duty cycle.
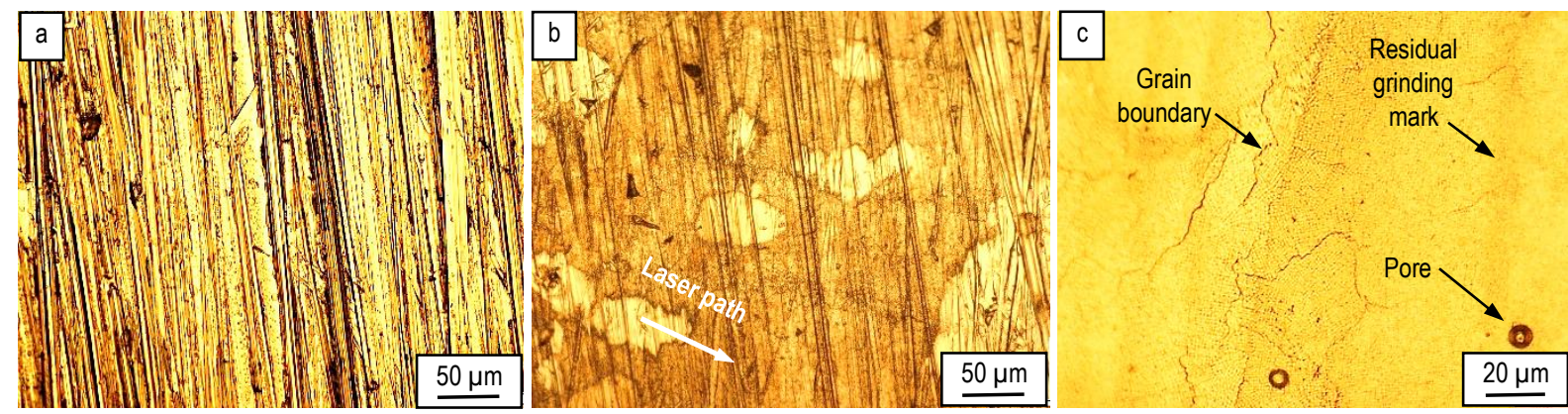

Figure 13: Evolution of surface polishing on L-PBF sample (a) ground surface, (b) partially polished surface, and (c) $0.45 \mu \mathrm{m}$ Ra polished surface. ECP at $1.2 \mathrm{~A} / \mathrm{mm}^{2}, 180 \mathrm{~s}, 75 \%$ duty cycle.

\subsection{Regression Models}

Regression models were derived for both extruded and L-PBF parts based on the experimental data for line roughness $R_{a}$ and area roughness $S_{a}$. These models were built using the extreme values of the parameters (Table 1 ) and then tested with the intermediate values to predict the accuracy of each model.

- Regression equations for L-PBF IN 718:

$$
\begin{gathered}
R a_{L P B F}=0.602-0.191 J-0.00021 t+0.0007 d_{c}-0.0493 d+0.0013(J \times t)+0.0014(J \times d c) \\
+0.248(J \times d) \\
S a_{L P B F}=0.490+0.370 J+0.00383 t+0.0040 d_{c}-0.0796 d-0.00005\left(t \times d_{c}\right)-0.000329(t \times d) \\
+0.00218\left(d_{c} \times d\right)
\end{gathered}
$$


- $\quad$ Regression equations for extruded IN 718:

$$
\begin{gathered}
R a_{\text {extrude }}=1.06-0.193 J-0.000635 t-0.0041 d_{c}-0.19 d+0.075(J \times d)+0.00273(d c \times d) \\
S a_{\text {extrude }}=0.975-0.373 J+0.00093 t+0.00577 d_{c}-0.0092 d+0.0044\left(J \times d_{c}\right)+0.1063(J \times d) \\
-0.000056(t \times d c)
\end{gathered}
$$

Where,

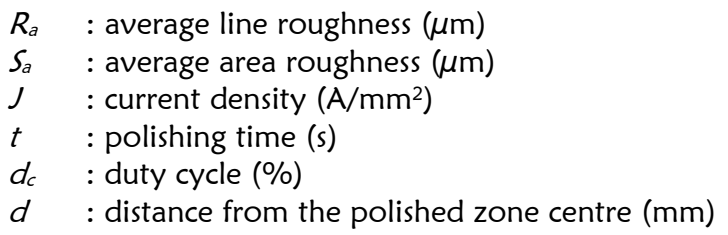

Table 6: Fitness values of regression models

\begin{tabular}{lcccc}
\hline Model & $R_{a}$ for L-PBF & $S_{a}$ for L-PBF & $R_{a}$ for extruded & $S_{a}$ for extruded \\
\hline $\mathrm{R}^{2}$ fitness value (\%) & 79 & 86 & 84 & 81 \\
\hline
\end{tabular}

- Line roughness: Equations (2) and (4) both indicated the higher impact of current density J over polishing time $t$ and duty cycle $d_{c}$. A higher current density would polish surface more and reduce its line roughness as expected.

- Surface roughness: Equations (3) and (5) also indicated current density as the most relevant parameter. When polishing the L-PBF samples, the positive signs for current density, polishing time, and duty cycle were due to accelerated etching rate of electrochemical reaction on (i) strained regions that surrounding defects such as nonconductive phases, pores and cracks, and (ii) the Nb depleted zone surrounding an NbC phase. Strain energy at a high dislocation density zone would lower the activation energy for chemical reaction to happen, therefore increasing the local etching rate. A high current density and longer time removed more matrix materials around the nonconductive phases, enlarge existing pores/crack while exposing additional defects embedded below the original surface.

On the contrary when polishing the extruded samples, the negative sign of current density suggested more effective polishing to smoothen a surface since (i) the small precipitates (e.g., $\delta, \gamma$ ', $\gamma$ ”) were dissolved with matrix ions, and (ii) lack of larger "inert" defects (e.g., void, Laves phases...) compared to the L-PBF samples.

- During the line roughness measurement, a 1-mm line was drawn in the matrix and did not cross any defect, therefore, its value represented the best possible scenario and was lower than the surface roughness values that represented everything within a $1-\mathrm{mm}^{2}$ area.

\section{CONCLUSIONS AND RECOMMENDATIONS}

Surfaces of Inconel 718 fabricated by laser-based powder bed fusion (L-PBF) and extrusion were successfully polished to submicron level by pulsed electrochemical polishing (ECP) process. This study found that:

1. The pulsed ECP produced a desirable isotropic polishing effect. Submicron surface finish was achieved within the ranges of chosen process variables for line roughness $\left(R_{a}\right)$ and area roughness $\left(S_{a}\right)$.

2. The niobium carbides, metallic carbides were found on both materials. However, the L-PBF samples contained additional Laves phases and voids that degraded the surface finish after electrochemically polished.

3. For the L-PBF samples, the best surface finish was $0.25 \mu \mathrm{m} R_{a}$ when polishing at $0.7 \mathrm{~A} / \mathrm{mm}^{2}, 75 \%$ duty cycle after 90s. Further polishing did not improve the surface finish due to the exposure of inherent nonconductive phases and defects in the materials. For the extruded samples, the best surface finish was $0.21 \mu \mathrm{m} R_{\mathrm{a}}$ when polishing at $0.7 \mathrm{~A} / \mathrm{mm}^{2}, 75 \%$ duty cycle after 270 s. The surface finish of extruded parts improved with higher polishing duration due to absence of material impurities beneath the surface.

4. Regression models for both area and line surface finish were presented. The $R^{2}$ values of all models were in the range $79-86 \%$. Such fitness value could be further improved with 5 -level parameter experimental studies.

5. Homogenizing and hot-isostatic pressing should be done to eliminate large Laves phases and pores prior to ECP for a uniform polished surface. Both of these thermal processes also anneal and eliminate any residual strains in the material, therefore, minimize the strain-induced accelerate etching at local areas. 


\section{ACKNOWLEDGEMENT}

The authors thank the KGSBO for providing the printed MAM samples, ESMA for the ECP equipment, EP System for the electrolyte, and the teacher participants who helped with experiments and collected surface finish data. Part of this work was funded by the National Science Foundation under grant \# 1711917.

\section{REFERENCES}

1. Schafrik RE, Ward DD, and Groh JR. Application of alloy 718 in GE aircraft engines: Past, present and next five years. Superalloys; 2001, 718(625): p. 1-11.

2. Choi JP, Shin GH, Yang S, Yang DY, Lee JS, Brochu M, and Yu JH. Densification and microstructural investigation of Inconel 718 parts fabricated by selective laser melting. Powder Technology; 2017, 310: p. 6066.

3. Jia $Q$ and Gu D. Selective laser melting additive manufacturing of Inconel 718 superalloy parts: Densification, microstructure and properties. Journal of Alloys and Compounds; 2014, 585: p. 713-721.

4. Sadiq MA, Hoang NM, Valencia N, Obeidat $S$, and Hung WNP. Experimental study of micromilling selective laser melted Inconel 718 superalloy. J. Procedia Manufacturing; 2018, 26:p. 983-992.

5. Special Metals, www.specialmetals.com, accessed Dec 2018.

6. Knorovsky GA, Cieslak MJ, Headley TJ, Romig AD, and Hammetter WF. Inconel 718: A Solidification Diagram. Metallurgical Transactions A; 1989: 20A, p. 2149-2158.

7. Trosch T, Strößner J, Völkl R, Glatzel U. Microstructure and mechanical properties of selective laser melted Inconel 718 compared to forging and casting. Materials Letters; 2016, 164: pp. 428-431. 164

8. Radavich JF. Electron metallography of alloy 718. Superalloys 718, 625, 706 and Various Derivatives. The Minerals, Metals \& Materials Society; 1997, p. 17-26.

9. Wang Z, Guan K, Gao M, Li X, Chen X, and Zeng X. The microstructure and mechanical properties of depositedIN718 by selective laser melting; Journal of Alloys and Compounds; 2012, 513: p.518-523.

10. Tucho WM, Cuvillier P, Sjolyst-Kverneland A, and Hansen V. Microstructure and hardness studies of Inconel 718 manufactured by selective laser melting before and after solution heat treatment. Materials Science and Engineering A; 2017, 689: p. 220-232.

11. Aghajani A, Tewes JP, Parsa AB, Hoffmann T, Kostka A, and Kloewer J. Identification of Mo-rich M23C6 carbides in alloy 718. Metallurgical and Materials Transactions A, 47(9); 2016. p. 4382-4392.

12. Zhang B, Li Y, and Bai Q. Defect formation mechanisms in selective laser melting: A review. Chinese Journal of Mechanical Engineering; 2017, 30(3): p. 515-527. doi:10.1007/s10033-017-0121-5.

13. Wang $X$, Gong $X$, and Chou K. Review on powder-bed laser additive manufacturing of Inconel 718 parts. Proceedings of the Institution of Mechanical Engineers, Part B: Journal of Engineering Manufacture; 2017, 231(11): p. 1890-1903.

14. Shi SQ, Gu D, Xia M, Cao S, and Rong T. Effects of laser processing parameters on thermal behavior and melting/solidification mechanism during selective laser melting of TiC/Inconel718 composites. Optics \& Laser Technology; 2016, 84, p. 9-22.

15. Huang CA and Chen YC. The effect of water content on the electropolishing behavior of Inconel 718 alloy in perchloric-acetic acid mixtures. Corrosion Science; 2009, 51(9): p. 1901-1906.

16. Yang L, O'Neil C, and Wu Y. The use of electropolishing surface treatment on in718 parts fabricated by laser powder bed fusion process; 2017.

17. Baicheng Z, Xiaohua L, Jiaming B, Junfeng GP, Wang CS, Muiling N, Guojun Q, and Jun W. Study of selective laser melting (SLM) Inconel 718 part surface improvement by electrochemical polishing. Materials \& Design; 2017, 116: p. 531-537.

18. Geethapriyan T, Kalaichelvan K, and Muthuramalingam T. Multi performance optimization of electrochemical micro-machining process surface related parameters on machining Inconel 718 using Taguchi-grey relational analysis. La Metallurgia Italina; 2016, 4: p. 13-19.

19. Feng Z, Granda E, and Hung NP. Experimental Investigation of Vibration-Assisted Pulsed Electrochemical Machining. Procedia Manufacturing; 2016, Vol. 5, p. 798-814.

20. Feng Z, Orona-Hinojos JM, Perez-Villanueva P, Lomeli P, and Hung WNP. Flushing Enhancement with Vibration and Pulsed Current in Electrochemical Machining. Journal of Engineering Materials and Manufacture; 2017, 2(4), p. 67-85.

21. Bhattacharyya B, Malapati M, Munda J, and Sarkar A. Influence of tool vibration on machining performance in electrochemical micro-machining of copper. International Journal of Machine Tools and Manufacture; 2007, 47(2): p. 335-342.

22. Rajurkar KP, Zhu D, McGeough JA, Kozak J, and De Silva A. New developments in electro-chemical machining. CIRP annals; 1999, 48(2): p. 567-579.

23. Bilgi DS and Jadhav PV. Enhancement of surface finish of Pulse Electrochemically Machined (PECM) surface using rotating electrode. Compuer Communincation and Information System; 2010, 2:1, p. 49-54.

24. Patel JB, Feng Z, Villanueva PP, and Hung WNP. Quality enhancement with ultrasonic wave and pulsed current in electrochemical machining," Procedia Manufacturing; 2017, 10: p. 662-673. 
25. Qu NS, Zhang QL, Fang XL, Ye EK, and Zhu D. Experimental Investigation on Electrochemical Grinding of Inconel 718. Procedia CIRP 35; 2015, pp. 16-19.

26. Bern RC and Salva RP. Additively manufactured Inconel alloy 718. 7th International Symposium on Superalloy 718 and Derivatives, The Minerals, Metals \& Materials Society, 2010, pp.455-469.

27. Mancisidor AM, Garciandia F, San Sebastian M, Álvarez P, Díaz J, and Unanue I. Reduction of the residual porosity in parts manufactured by selective laser melting using skywriting and high focus offset strategies. Physics Procedia; 2016, 83: p. 864-873.

28. Qi H, Azer M, and Ritter A. (2009). Studies of standard heat treatment effects on microstructure and mechanical properties of laser net shape manufactured Inconel 718. Metallurgical and Materials Transactions A; 2009, 40(10): p. 2410-2422.

29. Wang Z, Zhou D, Deng Q, Chen G, and Xie W. The microstructure and mechanical properties of Inconel 718 fine grain ring forging. Superalloy 718 and Derivatives; 2010, p. 343-349.

30. Kamata Y, Obikawa T, High speed MQL finish turning of Inconel 718 with different coated tools. Materials Processing Technology: 2007, p: 281-286.

31. Neda M, Sylvain T, and Vladimir B, Surface finish control of additively manufactured Inconel 625 components using combined chemical-abrasive flow polishing. Materials Processing Technology: 2018, p: 728-738. 